\title{
Cardiopulmonary Arrest and Resuscitation Disrupts Cholinergic Anti-Inflammatory Processes: A Role for Cholinergic $\alpha 7$ Nicotinic Receptors
}

\author{
Greg J. Norman, ${ }^{1}$ John S. Morris, ${ }^{1}$ Kate Karelina, ${ }^{2}$ Zachary M. Weil, ${ }^{2}$ Ning Zhang, ${ }^{2}$ Yousef Al-Abed, ${ }^{3}$ Holly M. Brothers, ${ }^{1}$ \\ Gary L. Wenk, ${ }^{1}$ Valentin A. Pavlov, ${ }^{3}$ Kevin J. Tracey, ${ }^{3}$ and A. Courtney DeVries ${ }^{2}$ \\ Departments of ${ }^{1}$ Psychology and ${ }^{2}$ Neuroscience, The Ohio State University, Columbus, Ohio 43210, and ${ }^{3}$ Laboratory of Biomedical Science, Feinstein \\ Institute for Medical Research, North Shore-LIJ Health System, Manhasset, NY 11030
}

\begin{abstract}
Cardiac arrest is a leading cause of death worldwide. While survival rates following sudden cardiac arrest remain relatively low, recent advancements in patient care have begun to increase the proportion of individuals who survive cardiac arrest. However, many of these individuals subsequently develop physiological and psychiatric conditions that likely result from ongoing neuroinflammation and neuronal death. The present study was conducted to better understand the pathophysiological effects of cardiac arrest on neuronal cell death and inflammation, and their modulation by the cholinergic system. Using a well validated model of cardiac arrest, here we show that global cerebral ischemia increases microglial activation, proinflammatory cytokine mRNA expression (interleukin- $1 \beta$, interleukin-6, tumor necrosis factor- $\alpha$ ), and neuronal damage. Cardiac arrest also induces alterations in numerous cellular components of central cholinergic signaling, including a reduction in choline acetyltransferase enzymatic activity and the number of choline acetyltransferasepositive neurons, as well as, reduced acetylcholinesterase and vesicular acetylcholine transporter mRNA. However, treatment with a selective agonist of the $\alpha 7$ nicotinic acetylcholine receptor, the primary receptor mediating the cholinergic anti-inflammatory pathway, significantly decreases the neuroinflammation and neuronal damage resulting from cardiac arrest. These data suggest that global cerebral ischemia results in significant declines in central cholinergic signaling, which may in turn diminish the capacity of the cholinergic anti-inflammatory pathway to control inflammation. Furthermore, we provide evidence that pharmacological activation of $\alpha 7$ nicotinic acetylcholine receptors provide significant protection against ischemia-related cell death and inflammation within a clinically relevant time frame.
\end{abstract}

\section{Introduction}

Sudden cardiac arrest (CA) affects millions of individuals each year and is a leading cause of mortality worldwide (American Heart Association, 2002). While mortality rates following cardiac arrest remain high, recent advances in resuscitation procedures (Püttgen et al., 2009) have improved survival and increased the need to explore interventions that can minimize the long-term neurological, psychological, and physical consequences of global

Received June 22, 2010; revised Sept. 23, 2010; accepted Dec. 11, 2010.

This work was supported by the National Institute of Neurological Disorders and Stroke Behavioral Core Grants P30 NS045758 (A.C.D.), R01HL080249 (A.C.D.), and R21MH077108 (A.C.D.). G.L.W. and H.M.B. were supported by National Institutes of Health Grant AG030331. Graduate students were supported by fellowships from the American Heart Association (K.K.) and The Ohio State University (J. Parker and Kathryn Webb Dinius Fellowship, G.J.N.). G.J.N. and A.C.D. designed the study. A.C.D., Y.A., G.W., V.P., K.T., and N.Z. provided conceptual input. Y.A., V.A.P., and K.T. provided the GTS-21. G.J.N. and J.S.M. provided the PCR and ELISA data. K.K., Z.M.W., and J.S.M. provided the histological data. N.Z. performed the CA/CPR. H.B. provided the ChAT activity data. G.J.N. and A.C.D. wrote the paper (all other authors provided editorial comments and approved the final draft).

We declare that, except for income received from our primary employers, no financial support or compensation has been received from any individual or corporate entity over the past 3 years for research or professional service and there are no personal financial holdings that could be perceived as constituting a potential conflict of interest.

Correspondence should be addressed to Greg J. Norman, The Ohio State University, 1835 Neil Avenue, Columbus, OH 43210. E-mail: norman.106@osu.edu.

G. J. Norman's present address: University of Chicago, Chicago, IL 60637.

DOI:10.1523/JNEUROSCI.4558-10.2011

Copyright $\odot 2011$ the authors $\quad 0270-6474 / 11 / 313446-07 \$ 15.00 / 0$ cerebral ischemia (Paradis et al., 2002; Bunch et al., 2003). Therefore, exploring new interventions that can counteract or minimize the adverse consequences of global cerebral ischemia as a result of cardiac arrest is critically important. One potential target is the immune system; immune dysregulation is a prominent feature of postresuscitation syndrome (Adrie et al., 2002) and can enhance neuronal damage in the days following successful resuscitation (Harukuni and Bhardwaj, 2006). Immune cells, such as microglia and macrophages, become activated soon after cerebral ischemia and begin to increase the production and release of cytotoxic agents, including cytokines, matrix metalloproteinases, nitric oxide, and reactive oxygen species (Wang et al., 2007), which can contribute to neuronal cell death, as well as disruption of the blood-brain barrier (Danton and Dietrich, 2003; Kidwell et al., 2008). Although moderate levels of neuroinflammation are protective in some contexts (Lambertsen et al., 2009), an inability to control extreme inflammation following cerebral ischemia exacerbates neural injury (Allan et al., 2005; Harukuni and Bhardwaj, 2006).

Acetylcholine $(\mathrm{ACh})$ is a potent physiological regulator of central and peripheral inflammation (Tracey, 2009), in addition to its well known role in motor, cognitive, and affective processes (Berntson et al., 1998; Sarter and Parikh, 2005). Dysregulation of 
cholinergic signaling has been implicated in a wide range of inflammatory disorders including Alzheimer's disease (Wenk and Willard, 1998), cerebral hemorrhage (Lee et al., 2010), and sepsis (Adrie et al., 2002; Tracey, 2009). In contrast, treatment with exogenous ACh agonists reduces experimentally induced inflammation (Tracey, 2009). Activity at cholinergic $\alpha 7$ nicotinic acetylcholine receptors ( $\alpha 7 \mathrm{nAChRs})$ mediate the majority of the effects of ACh on the immune system (Tracey, 2009), and both neurons and microglia express functional $\alpha 7 \mathrm{nAChRs}$ (Sharma and Vijayaraghavan, 2002; Sarter and Parikh, 2005). Indeed, activity at microglial $\alpha 7 \mathrm{nAChRs}$ influences glial activation (Ohnishi et al., 2009), proinflammatory cytokine production (Rosas-Ballina et al., 2009), and the expression of reactive oxygen species (Moon et al., 2008) in vitro. Similarly, activation of $\alpha 7 \mathrm{nAChR}$ attenuates inflammation in a myriad of in vivo disease models, including sepsis, arthritis, and myocardial ischemia (Tracey, 2009). Thus, a decline in cholinergic neurotransmission following brain injury may diminish the capacity of the CNS to control run-away inflammation (Tracey, 2009). Neuronal cell death following CA/ cardiopulmonary resuscitation $(\mathrm{CA} / \mathrm{CPR})$ is predominantly located in "watershed" areas, such as the hippocampus (Böttiger et al., 1999), a structure densely populated with $\alpha 7 \mathrm{nAChRs}$ (Gotti et al., 2006). We reasoned that the loss of cholinergic functioning following cerebral ischemia may compromise the physiological regulation of inflammation and cell survival mechanisms, and that treatments aimed at restoring aspects of cholinergic signaling may prove beneficial.

The objective of the present study was to determine whether cardiac arrest disrupts the cholinergic signaling and its associated anti-inflammatory properties. Here, we report that global cerebral ischemia causes an increase in central and peripheral inflammation, an increase in neuronal death, and a reduction in forebrain ACh. Furthermore, concurrent treatment with a selective $\alpha 7 \mathrm{nAChR}$ agonist (GTS-21) reduces postischemic inflammation and neuronal damage; the beneficial effects of GTS-21 were eliminated by treatment with mecamylamine, an $\alpha 7 \mathrm{nAChR}$ antagonist.

\section{Materials and Methods}

Adult male C57BL/6 mice (23-30 g; Charles River) were maintained on a $14 / 10 \mathrm{~h}$ light/dark cycle and individually housed within a temperatureand humidity-controlled vivarium. The study was conducted in accordance with National Institutes of Health $(\mathrm{NIH})$ guidelines and was approved by The Ohio State University Institutional Animal Care and Use Committee.

\section{Experimental protocols}

Study 1: the influence of global cerebral ischemia on substrates of cholinergic signaling. Animals were randomly assigned to one of six experimental groups: the first two groups survived for $3 \mathrm{~d}$ following surgery, and then their tissue was processed for mRNA analysis (control, $n=15$; normothermic CA/CPR, $n=10$ ). For the purposes of histological analysis, another cohort of animals survived for $7 \mathrm{~d}$ following either normothermic CA/CPR $(n=10)$ or control surgeries $(n=15)$. The control groups consisted of hypothermic CA/CPR $(n=7)$ and sham $(n=8)$ animals (see below, CA/CPR procedure, for detailed surgery description); consistent with previous reports (Neigh et al., 2004; Norman et al., 2010), the sham and hypothermic groups did not differ from one another on any of the dependent measures and were subsequently collapsed into a single control group for statistical comparisons. An additional 20 mice (control, $n=10$; normothermic CA/CPR, $n=10$ ) survived for $7 \mathrm{~d}$ following surgery for analysis of choline acetyltransferase (ChAT) enzymatic activity.

Study 2: assessing the role of pharmacological stimulation of $\alpha 7 n A C h R$ following $C A / C P R$. Mice were randomly assigned to experimental groups surviving 3 or $7 \mathrm{~d}$. Within the $3 \mathrm{~d}$ survival cohort, groups consisted of control $(n=16)$ and normothermic CA/CPR $(n=9)$ animals treated with either $4 \mathrm{mg} / \mathrm{kg}$ GTS- 21 or vehicle (isotonic saline; $n \geq 8 /$ group). To confirm that the effects of GTS-21 were dependent on nicotinic receptors, the selective nicotinic receptor antagonist mecamylamine $(1 \mathrm{mg} / \mathrm{kg})$ was administered daily along with GTS-21 $(4 \mathrm{mg} / \mathrm{kg})$ to a cohort of normothermic CA/CPR animals $(n=8)$. As in study 1 , the sham $(n=8)$ and hypothermic CA/CPR $(n=8)$ groups did not differ statistically from one another and were subsequently collapsed into a single control group for statistical analysis and graphic representation.

$C A / C P R$ procedure. Mice were anesthetized with isoflurane, and then 8 min of cardiac arrest was induced via potassium chloride $(50 \mu \mathrm{l}, 0.5 \mathrm{M}$, $\left.4^{\circ} \mathrm{C}\right)$. CPR was initiated via injection of epinephrine ( $16 \mu \mathrm{g}$ in $0.6 \mathrm{cc}$ of saline, $37^{\circ} \mathrm{C}$ ) and chest compressions (300/min). To protect against peripheral organ damage in all mice, the periphery was maintained at $27^{\circ} \mathrm{C}$ during CA/CPR. A double-lumen coil system was used to manipulate head temperature independently of body temperature; the brains of experimental animals were maintained at $37^{\circ} \mathrm{C}$ (normothermic), while the brains of the ischemic controls were maintained at $27^{\circ} \mathrm{C}$ (hypothermic) to prevent CA/CPR-induced neuroinflammation and neuronal damage (Neigh et al., 2009). The sham animals underwent the same surgical procedures and temperature manipulations as the CA animals, except that isotonic saline was injected instead of potassium chloride and epinephrine, and no CPR was performed.

\section{Drug treatment}

GTS-21 was dissolved in saline (vehicle) and administered intraperitoneally daily at a dose of $4 \mathrm{mg} / \mathrm{kg}$, beginning $24 \mathrm{~h}$ after CA/CPR. Peripherally administered GTS-21 has a biological half-life of 12-24 h (Pavlov et al., 2007) and readily crosses the blood-brain barrier (Briggs et al., 1997; Mahnir et al., 1998). In a subset of animals, mecamylamine was coadministered ( $1 \mathrm{mg} / \mathrm{kg}$, i.p., in isotonic saline) with GTS-21. The clearance half-life of mecamylamine is $10.1 \mathrm{~h}$ in plasma (Young et al., 2001). Peripherally administered mecamylamine rapidly accumulates within the hippocampus with concentrations following peripheral administration (Debruyne et al., 2003).

\section{$m R N A$ analysis}

Brain tissue was collected $3 \mathrm{~d}$ after CA/CPR using aseptic techniques; this time point was chosen because it corresponds with peak neuroinflammation preceding neuronal death from CA/CPR. Hippocampi were dissected, and total RNA was extracted from $>30 \mathrm{mg}$ of individual hippocampi using an homogenizer (Ultra-Turrax T8, IKA Works) and an RNeasy Mini Kit according to manufacturer's protocol (Qiagen). cDNA was created via reverse transcription of $2 \mu \mathrm{g}$ of RNA from each sample with MMLV Reverse Transcriptase enzyme (Invitrogen) according to the manufacturer's protocol.

A TaqMan 18S Ribosomal RNA primer and probe set (labeled with VIC fluorescent dye; Applied Biosystems) was used as an internal control and normalization. Proinflammatory cytokine mRNA levels of interleukin-1 $\beta$ (IL-1 $\beta$ ), tumor necrosis factor $\alpha$ (TNF- $\alpha$ ), IL-6, glial markers glial fibrillary acidic protein (GFAP), and CD11b (Mac-1), acetylcholinesterase (AChE), ChAT, vesicular ACh transporter (vAChT), and high-affinity choline transporter-1 (ChT1) were analyzed using inventoried primer and probe kits purchased from Applied Biosystems. The universal two-step reverse transcriptase PCR cycling conditions used were as follows: $50^{\circ} \mathrm{C}$ for $2 \mathrm{~min}, 95^{\circ} \mathrm{C}$ for $10 \mathrm{~min}$, followed by 40 cycles of $95^{\circ} \mathrm{C}$ for $15 \mathrm{~s}$ and $60^{\circ} \mathrm{C}$ for $1 \mathrm{~min}$. Relative gene expression of individual samples run in duplicate was calculated by comparison to a relative standard curve and then normalized to the ribosomal RNA subunit $18 \mathrm{~s}$ (a housekeeping gene) to control for global changes in gene expression and experimental error. Amplification was performed on an ABI $7000 \mathrm{Se}-$ quencing Detection System by using Taqman Universal Master Mix (Applied Biosystems).

\section{Histology}

Tissue collection. At $7 \mathrm{~d}$ post-reperfusion, mice were deeply anesthetized and a blood sample was collected. Animals were perfused transcardially with ice-cold $0.1 \mathrm{M}$ PBS and 4\% paraformaldehyde. Brains were removed, postfixed overnight in $4 \%$ paraformaldehyde, cryoprotected with $30 \%$ 

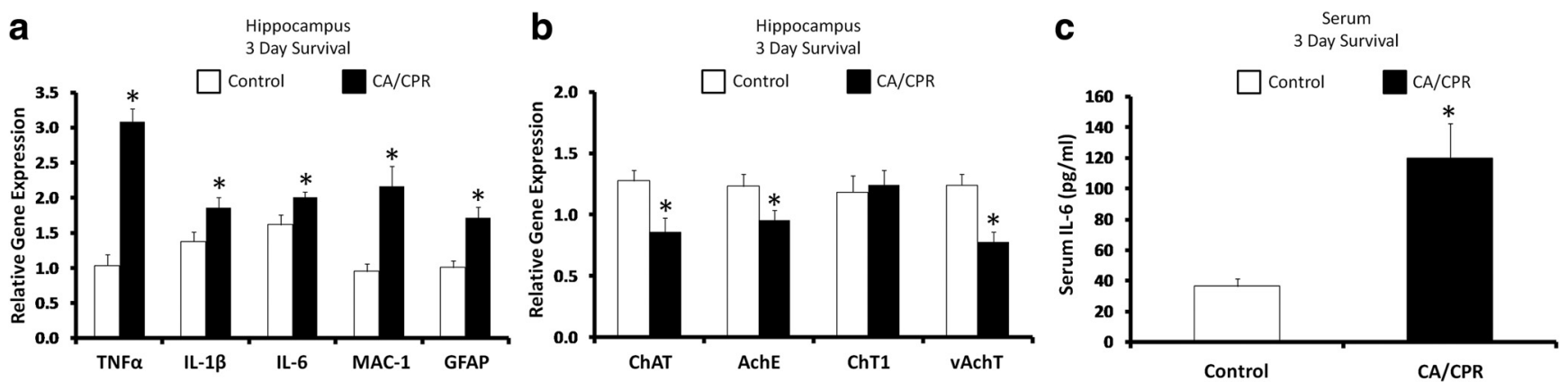

Figure 1. Global cerebral ischemia increases proinflammatory cytokine mRNA expression and decreases mRNA expression of functional substrates of cholinergic signaling at $3 \mathrm{~d}$ following surgery. $\boldsymbol{a}$, At $3 \mathrm{~d}$ following surgery, the CA/CPR animals displayed increased hippocampal mRNA levels of the proinflammatory cytokines TNF $\alpha$, IL-1 $\beta$, and IL-6. Similarly, the neuroglia markers MAC- 1 and GFAP were increased in CA/CPR animals compared with controls. $\boldsymbol{b}$, The CA/CPR procedure resulted in significant reductions in hippocampal levels of cholinergic signaling substrates $C h A T$, AChE, and vAChT but not ChT1. Data represent the ratio of the expression of the gene of interest relative to the housekeeping gene 18s. C, Circulating levels of IL- 6 were elevated in CA/CPR animals compared with controls at $3 \mathrm{~d}$ following surgical manipulation. Data are presented as mean \pm SEM. An asterisk (*) indicates a statistically significant difference from control ( $p<0.05)$.

sucrose, and then frozen on dry ice. Brains were sectioned at $14 \mu \mathrm{m}$ on a cryostat and thaw-mounted onto Super Frost Plus slides (Fisher). Slides were stored at $-20^{\circ} \mathrm{C}$ until further processing. Separate slides were processed for Fluoro-Jade C, Mac-1, ChAT, and AchE. For each stain, one section per animal was analyzed; coronal sections between -1.6 and $-1.8 \mathrm{~mm}$ caudal to bregma were selected for hippocampal measurements, and sections between 1.1 and $1.3 \mathrm{~mm}$ caudal to bregma were selected for the basal forebrain measurements (Franklin and Paxinos, 1996). Data collection was performed by an individual who was not informed of individual group assignments.

Fluoro-Jade C histochemistry. Slides containing $14 \mu \mathrm{m}$ sections were stained according to established protocols (Schmued and Hopkins, 2000). Slides were dried at room temperature, immersed in a basic ethanol solution and then rinsed in 70\% ethanol and distilled water. Slides were then treated with potassium permanganate $(0.06 \%)$ for $10 \mathrm{~min}$, rinsed with water, and then incubated in Fluoro-Jade C $(0.0001 \%$ in a $1 \%$ acetic acid solution); sections were rinsed in $\mathrm{dH}_{2} \mathrm{O}$, and dried on a slide warmer and coverslipped with DPX (Sigma). Consistent with previous studies (Weil et al., 2008, 2009; Norman et al., 2010), Fluoro-Jade C-positive cells were counted in the hippocampus (CA1, CA2, CA3, and dentate gyrus). Images of fluorescently stained sections were captured with a digital camera (Axiocam, Zeiss) connected to a fluorescent microscope (Axioskop, Zeiss) using Axiovision software (Zeiss).

Mac-1 histochemistry. Microglia were visualized using an antibody directed against Mac- 1 . Following quenching in $\mathrm{H}_{2} \mathrm{O}_{2}$ and methanol, slides were incubated for $24 \mathrm{~h}$ at room temperature with rat anti-Mac- 1 antibody (Serotec) diluted 1:100 in phosphate buffer containing 0.3\% Triton $\mathrm{X}-100$, rabbit serum, and bovine serum albumin. Slides were then rinsed and incubated with rabbit anti-rat secondary antibody (1:500; Vector Laboratories) for $2 \mathrm{~h}$. Sections were then rinsed and treated with Elite $A B C$ reagent for $60 \mathrm{~min}$. Sections were again rinsed with phosphate buffer solution and then visualized with $\mathrm{DAB}$ (3,3'-diaminobenzidine) containing nickel. After visualization, slides were rinsed in distilled water, then dehydrated, cleared, and coverslipped.

Proportional area analysis was used as an index of microglial activation; the hypertrophy that occurs when microglia become activated increases surface staining area (Popovich et al., 1997). Briefly, a fixed size rectangular "scan box" was superimposed over the hippocampus in each image, and the percentage of the stained area within the box was recorded (ImageJ, NIH). The proportional area was calculated as the percentage of the tissue stained relative to the entire scan box area (Weil et al., 2009).

ChAT expression. Brain sections were treated for antigen retrieval by immersion in proteinase $\mathrm{K}(20 \mathrm{mg} / \mathrm{ml})$ for $10 \mathrm{~min}$ at $37^{\circ} \mathrm{C}$. Slides were then rinsed in $0.1 \mathrm{M}$ PBS, quenched in $\mathrm{H}_{2} \mathrm{O}_{2}$, rinsed again, and blocked with goat serum. Slides were incubated for $24 \mathrm{~h}$ at room temperature with an antibody to ChAT (1:500, Millipore), then rinsed and incubated with anti-rabbit secondary antibody (1:500, Vector Laboratories) for $2 \mathrm{~h}$. Sections were then treated with Elite $\mathrm{ABC}$ reagent and then visualized with diaminobenzidine containing nickel (Vector Laboratories). ChAT- positive cells were counted within the entire basal forebrain (nucleus basalis, diagonal band of Broca, and medial septal nuclei) and the entire hippocampus (CA1, CA2, CA3, and dentate gyrus), and then summed to form single estimates of ChAT-positive cells within the entire hippocampus and basal forebrain.

AChE expression. Tissue was quenched in $\mathrm{H}_{2} \mathrm{O}_{2}$, rinsed in $0.1 \mathrm{M}$ maleate buffer, then incubated for $45 \mathrm{~min}$ at room temperature in $0.0025 \%$ acetylthiocholine, $0.25 \%$ sodium citrate, $0.5 \%$ copper sulfate, and $0.5 \%$ potassium ferrocyanide in $0.1 \mathrm{M}$ maleate buffer. Sections were then rinsed and visualized with diaminobenzidine containing nickel. Photographs of hippocampus (CA1, CA2, CA3, and dentate gyrus) and basal forebrain (nucleus basalis, diagonal band of Broca, and medial septal nuclei) were digitized, an analysis window was superimposed onto the region of interest (hippocampus or basal forebrain), and proportional stained areas were assessed using ImageJ software (NIH).

IL-6 protein quantification. Blood samples were collected at 3 and $7 \mathrm{~d}$ following surgery and immediately centrifuged at $6000 \mathrm{rpm}$ for $30 \mathrm{~min}$ at $4^{\circ} \mathrm{C}$; sera were collected, aliquoted, and stored at $-80^{\circ} \mathrm{C}$ until assayed. Serum samples were then assayed for IL-6 using a sandwich ELISA kit (BD Biosciences) according to manufacturer's protocol. As a result of the large amount of sample needed to conduct ELISA, the assay was limited to one protein; IL- 6 was chosen based upon its proposed role in the development of various pathophysiological responses associated with ischemia (Smith et al., 2004).

ChAT activity. Samples consisting of one hemisphere per animal were assayed for endogenous ChAT activity as determined by the formation of $\left[{ }^{14} \mathrm{C}\right]$ acetylcholine from $\left[{ }^{1-14} \mathrm{C}\right]$ acetyl-coenzyme $\mathrm{A}(\mathrm{CoA})$ and choline, as previously described (Wenk et al., 2003). Protein concentrations were determined by Bradford assay; all assays were performed in triplicate.

\section{Results}

Global cerebral ischemia is associated with increased mRNA expression of proinflammatory cytokines and altered cellular components of central cholinergic signaling

As expected, global cerebral ischemia resulted in increased hippocampal expression of the proinflammatory cytokines TNF $\alpha$ $\left(F_{(1,23)}=55.96, p<0.05\right)$, IL-1 $\beta\left(F_{(1,23)}=4.64, p<0.05\right)$, IL-6 $\left(F_{(1,23)}=4.90, p<0.05\right)$, Mac-1 $\left(F_{(1,23)}=4.32, p<0.05\right)$, and $\operatorname{GFAP}\left(F_{(1,23)}=30.34, p<0.05\right)$ at $3 \mathrm{~d}$ following surgery (Fig. $\left.1 a\right)$ compared with controls. Additionally, normothermic CA/CPR animals displayed reduced hippocampal mRNA levels of the enzyme responsible for acetylcholine synthesis, $\operatorname{ChAT}\left(F_{(1,23)}=\right.$ 11.63, $p<0.05$ ) (Fig. $1 b)$, as well as $\operatorname{AChE}\left(F_{(1,23)}=5.02, p<\right.$ $0.05)$ (Fig. $1 b)$ and vAChT $\left(F_{(1,23)}=6.02, p<0.05\right)$ (Fig. $1 b$ ), which are responsible for synaptic clearance of ACh and the loading of ACh into synaptic vesicles, respectively. No group differences were detected for the $\operatorname{ChT} 1\left(F_{(1,23)}=0.20, p>0.05\right)$ (Fig. 

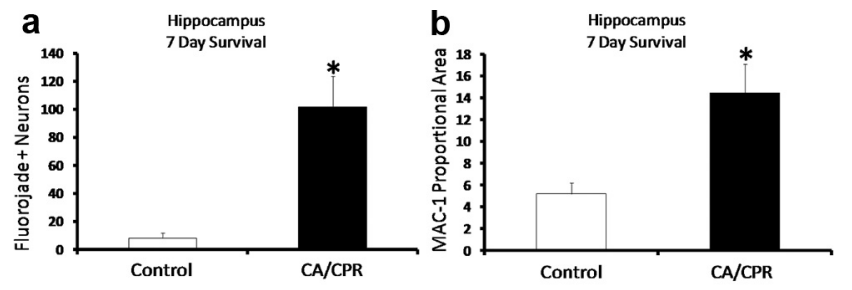

C

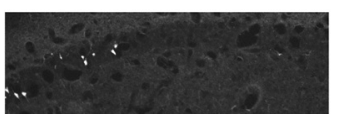

e
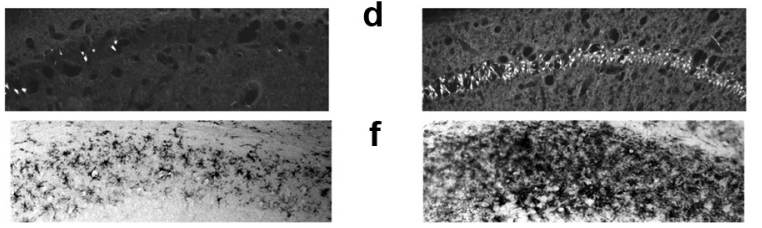

f

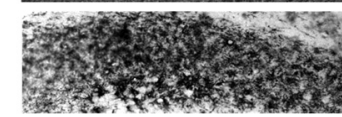

Figure 2. Global cerebral ischemia increases neuroinflammation and cell death responses at $7 \mathrm{~d}$ following surgery. $\boldsymbol{a}, \boldsymbol{b}$, The CA/CPR procedure increased levels of hippocampal cell damage $(\boldsymbol{a})$ and microglial expression $(\boldsymbol{b})$ at $7 \mathrm{~d}$ following surgery, as indicated by Fluoro-Jade $\mathrm{C}$ and MAC-1 staining, respectively. Representative photomicrographs of cell death within CA1 region of the hippocampus in control (c) and CA/CPR (d) animals. $\boldsymbol{e}, \boldsymbol{f}$, Representative photomicrographs of microglia activation within the CA1 region of the hippocampus in control $(\boldsymbol{e})$ and CA/CPR $(\boldsymbol{f})$ animals. Data are presented as mean $\pm \mathrm{SEM}$. An asterisk $\left({ }^{*}\right)$ indicates a statistically significant difference from control $(p<0.05)$.

a

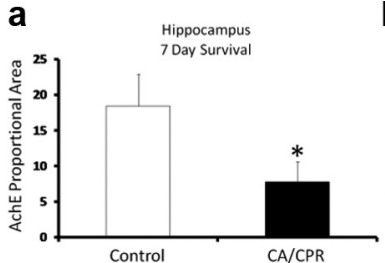

d

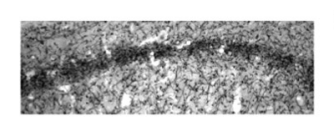

f

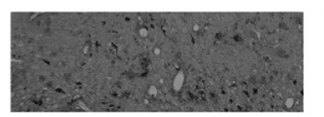

b

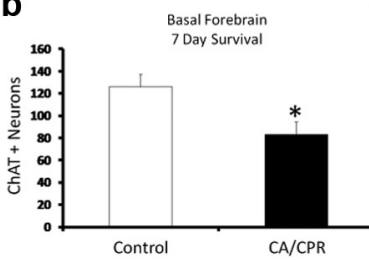

e

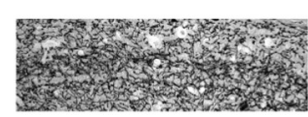

$\mathbf{g}$

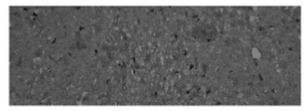

C

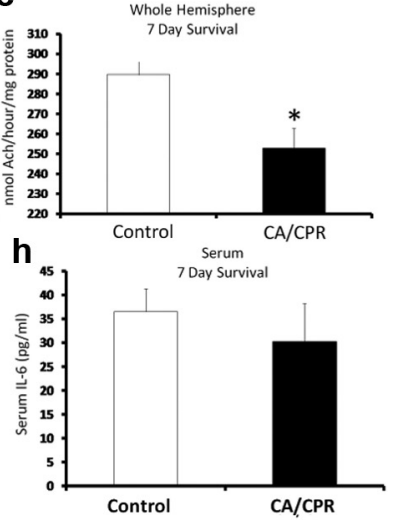

Figure 3. Global cerebral ischemia diminishes the number of choline acetyltransferase + neurons, choline acetyltransferase enzymatic activity, and the level of acetylcholinesterase at $7 \mathrm{~d}$ following surgery. $\boldsymbol{a}, \boldsymbol{b}$, The CA/CPR procedure decreased AChE levels within the hippocampus ( $\boldsymbol{a}$ ) and decreased ChAT-positive neurons within the basal forebrain (b). $\boldsymbol{c}$, CA/CPR animals displayed diminished ChAT activity at $7 \mathrm{~d}$ following surgery, as determined by the formation of $\left[{ }^{14} \mathrm{C}\right]$ acetylcholine from $\left[{ }^{1-14} \mathrm{C}\right]$ acetyl-CoA and choline in whole-brain tissue. $\boldsymbol{d}, \boldsymbol{e}$, Representative photomicrographs of AChE within the CA1 region of the hippocampus in control ( $\boldsymbol{d}$ ) and CA/CPR (e) animals. $\boldsymbol{f}, \boldsymbol{g}$, Representative photomicrographs of ChAT-positive neurons within the medial septal nucleus (basal forebrain substructure), a primary source of cholinergic innervation of the hippocampus, in control (f) and CA/CPR (g) animals. $\boldsymbol{h}$, The CA/CPR procedure had no influence on circulating levels of IL- 6 at $7 \mathrm{~d}$ following surgery. Data are presented as mean \pm SEM. An asterisk $(*)$ indicates a statistically significant difference from control $(p<0.05)$.

1b). These results indicate that CA/CPR engenders an increase in hippocampal proinflammatory cytokine mRNA levels and microglial markers, and widespread alterations in central cholinergic signaling.

The effects of global cerebral ischemia on neuronal cell death, neuroinflammation, and central cholinergic signaling

Normothermic CA/CPR animals displayed elevated serum IL-6 protein levels at $3 \mathrm{~d}$ following surgery $\left(F_{(1,24)}=25.26 p<0.05\right)$ (Fig. 1c). Similarly, CA/CPR animals had significantly more Fluoro Jade C-positive neurons within the hippocampus compared with controls $\left(F_{(1,24)}=21.45, p<0.05\right)$ (Fig. 2a,c,d). A similar pattern was apparent for microglial expression; normothermic CA/CPR animals displayed a significant increase in Mac-1 proportional area within the hippocampus at $7 \mathrm{~d}$ follow-

ing surgery relative to control animals $\left(F_{(1,24)}=5.08, p<0.05\right)$ (Fig. 2b,e,f).

Histological analysis revealed that CA/CPR animals had diminished hippocampal AChE levels $\left(F_{(1,24)}=6.00, p<0.05\right)$ (Fig. $3 a, d, e$ ), in conjunction with reduced numbers of ChATpositive neurons within the basal forebrain, compared with controls $\left(F_{(1,24)}=6.32, p<0.05\right)$ (for representative photomicrographs of ChAT-positive neurons in the basal forebrain, see Fig. $3 b, f, g)$; the basal forebrain is a primary source of cholinergic innervation of the hippocampus.

In keeping with the histological and mRNA analysis reported above, the enzymatic activity of ChAT was found to be significantly decreased in normothermic CA/CPR animals compared with controls $\left(F_{(1,18)}=4.77, p<0.05\right)$ (Fig. $\left.3 c\right)$. Finally, circulating IL-6 levels were not different between $\mathrm{CA} / \mathrm{CPR}$ and controls at $7 \mathrm{~d}$ following (Fig. $3 h)$. These data show that central cholinergic signaling, which may be associated with pathophysiological processes.

Pharmacological cholinergic stimulation by the $\alpha 7 \mathrm{nAChR}$ agonist GTS-21 following global cerebral ischemia decreases cell death and neuroinflammation

Daily treatment with $4 \mathrm{mg} / \mathrm{kg}$ GTS-21 beginning $24 \mathrm{~h}$ following CA/CPR significantly decreased mRNA expression of hippocampal TNF $\alpha\left(F_{(1,45)}=6.43, p<\right.$ 0.05; Tukey $<0.05$ ) (Fig. $4 a$ ) and Mac-1 $\left(F_{(1,45)}=6.57, p<0.05\right.$; Tukey $\left.<0.05\right)$ (Fig. $4 a$ ) at $3 \mathrm{~d}$ following surgery compared with vehicle-treated normothermic CA/CPR and control animals. Similarly, GTS-21 reduced serum levels of IL- 6 at $3 \mathrm{~d}$ following surgery $\left(F_{(1,45)}=17.90, p<\right.$ 0.05; Tukey $<0.05$ ) (Fig. $4 b$ ).

GTS-21 did not significantly alter mRNA levels of IL- $1 \beta$, IL- 6 , or GFAP $(p>0.05)$. Animals treated with GTS-21 displayed decreased cell death $\left(F_{(3,53)}=\right.$ 24.12, $p<0.05$; Tukey $<0.05$ ) (Fig. $4 c, e, f, g)$ and microglial activation $\left(F_{(3,53)}\right.$ $=15.10, p<0.05$; Tukey $<0.05$ ) (Fig. $4 d, h, i, j)$ at $7 \mathrm{~d}$ following CA/CPR compared with vehicle-treated controls, GTS21-treated animals, and GTS-21 + mecamylamine (nAChR antagonist)treated normothermic CA/CPR animals.

As can be seen in Figure 4, simultaneous administration of the selective nicotinic antagonist mecamylamine with GTS-21 to CA/CPR animals eliminated the effects of GTS-21 on neuronal cell death $(p<0.05)$ and microglial expression $(p<0.05)$ (Fig. $4 c, d)$, confirming the role of nAChR in mediating the effects of GTS-21.

\section{Discussion}

The cholinergic system is important for maintaining appropriate central and peripheral immune responses (Tracey, 2009). The guiding hypothesis for the current study was that ischemiainduced cholinergic and immunological dysregulation contribute to impaired recovery following cardiac arrest. In our model, $\mathrm{CA} / \mathrm{CPR}$ results in substantial increases in mRNA expression of the proinflammatory cytokines $\mathrm{TNF} \alpha$ and IL- $1 \beta$ in the hippocampus $3 \mathrm{~d}$ following surgery compared with controls (Fig. 
1a). Neuroinflammation following cerebral ischemia is a major contributor to neuronal cell death (Harukuni and Bhardwaj, 2006), and causal roles have been established for these two proinflammatory cytokines. Indeed, inhibition of TNF- $\alpha$ and IL- $1 \beta$ reduces damage resulting from ischemic injury (Yang et al., 1998), while administration of proinflammatory cytokines after the onset of ischemia worsens ischemic brain damage (Barone et al., 1997). Expression of IL-6 mRNA, a pleiotropic cytokine that has both pro- and anti-inflammatory effects depending on location and time course, was also increased in the hippocampus and serum at $3 \mathrm{~d}$ following CA/CPR, compared with control.

The observed increase in proinflammatory cytokines may be related to postischemic alterations in the activities of microglia and astrocytes; the primary regulators of central inflammatory responses. Hippocampal mRNA levels of MAC-1 and GFAP, markers of microglia and astrocytes, respectively, were significantly elevated at $3 \mathrm{~d}$ following CA/CPR relative to the ischemic control (Fig. 1a). A similar pattern of MAC-1 expression and neuronal damage was observed on postischemic day 7 (Fig. 2a-f). Microglia are thought to contribute to neuronal cell death following global cerebral ischemia (Neigh et al., 2009); pharmacological inhibition of microglial activation following CA/CPR inhibits cell death responses and improves behavioral outcome (Neigh et al., 2009).

In addition to the effects on central and peripheral inflammatory processes, CA/ CPR influences numerous cellular substrates known to mediate functional cholinergic transmission. Indeed, $3 \mathrm{~d}$ fol-

lowing CA/CPR, mRNA levels of ChAT, AChE, and vAChT were diminished in the hippocampus compared with the ischemic control group (Fig. 1b). Furthermore, CA/CPR reduced the number of ChAT-positive neurons within the basal forebrain (Fig. 3b), a primary source of hippocampal cholinergic innervation (Sarter and Parikh, 2005), and caused a significant reduction in ChAT activity relative to the ischemic control (Fig. $3 c$ ). Similarly, CA/CPR decreased the number of AChE-positive neurons within the hippocampus at $7 \mathrm{~d}$ following surgery (Fig. $3 a$ ).

The modulation of various components of central cholinergic signaling following cerebral ischemia decreases the production of Ach (Cooper, 1994; Wenk and Willard, 1998), which in turn may contribute to pathological levels of inflammation through diminished signaling at $\alpha 7 \mathrm{nAChR}$. Consistent with this line of reasoning, treatment with GTS-21, a centrally acting cholinergic $\alpha 7 \mathrm{nAChR}$ agonist, beginning $24 \mathrm{~h}$ after CA/CPR reduced circulating levels of IL-6 and hippocampal TNF- $\alpha$ and MAC- 1 mRNA expression at $3 \mathrm{~d}$ following CA/CPR (Fig. 4a). Likewise, daily treatment with GTS-21 decreased hippocampal cell death and microglial expression within the hippocampus at $7 \mathrm{~d}$ following $\mathrm{CA} / \mathrm{CPR}$, while simultaneous
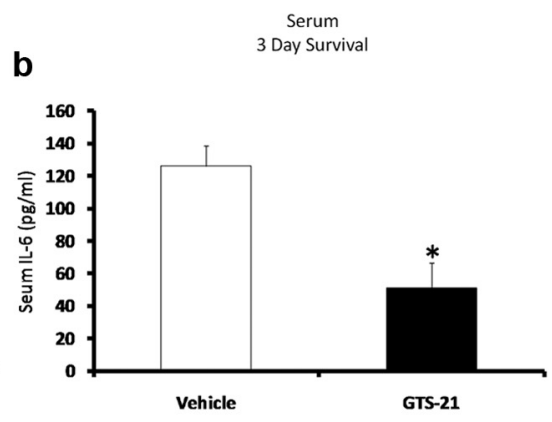

d
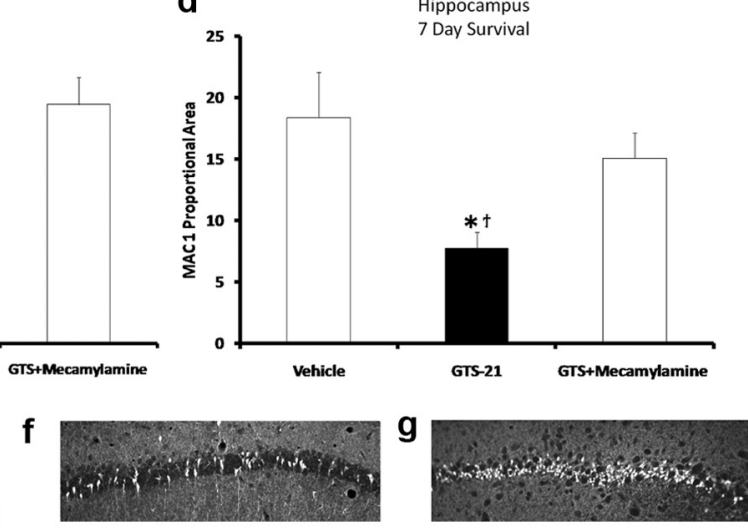

\section{i}
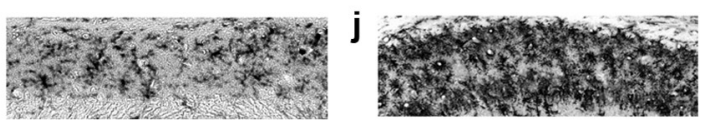

Figure 4. Daily pharmacological stimulation of $\alpha 7$ nicotinic cholinergic receptors decreases cerebral ischemia-associated prohippocampus in vehicle-treated animals (e), GTS-21-treated animals $(\boldsymbol{f})$, and animals treated with both GTS-21 and the nicotinic antagonist mecamylamine $(\boldsymbol{g}) \cdot \boldsymbol{h}-\boldsymbol{j}$, Representative photomicrographs of microglia activation within the CA1 region of the hip(j). Data are presented as mean \pm SEM. An asterisk $\left({ }^{*}\right)$ indicates a statisticallysignificant difference from control $(p<0.05)$. totatistically significant difference from GTS-21 + mecamylamine.

treatment with a selective $\mathrm{nAChR}$ antagonist eliminated the beneficial effects of GTS-21 (Fig. $4 c-j$ ). Interestingly, GTS-21 treatment significantly reduced IL- 6 protein concentrations in serum, while having no apparent effect on IL-6 mRNA expression in the hippocampus (Fig. 4a,b). This apparent discrepancy in outcome could reflect the distinct mechanisms controlling IL-6 expression in the brain versus periphery (Chapman et al., 2009; Suzuki et al., 2009). Indeed, IL-6 protein concentrations in the brain and periphery after focal cerebral ischemia can be inversely related under some circumstances (Karelina et al., 2009). Thus, CA/CPR disrupts central cholinergic transmission at multiple points, and restoration of one aspect of cholinergic signaling at $\alpha 7 \mathrm{nAChR}$ has mitigating effects on several, but not all, of the pathophysiological responses to global cerebral ischemia.

Of particular interest to the present study, $\alpha 7$ nicotinic receptors are expressed on neurons, monocytes, and microglia across various brain regions, including the hippocampus (Youngquist et al., 2009), and GTS-21 diminishes serum cytokine production following immune stimulation (Rosas-Ballina et al., 2009). Thus, the broad and diverse distribution of $\alpha 7 \mathrm{nAChR}$ within the brain 
provides a potential substrate through which centrally acting cholinergic agents, such as GTS-21, acting on the $\alpha 7 \mathrm{nAChR}$ are able to influence cell death and inflammatory processes following cerebral ischemia. Importantly, GTS-21 is capable of crossing the blood-brain barrier (Mahnir et al., 1998) where it can act directly upon central $\alpha 7 \mathrm{nAChR}$ and has been used safely in humans to treat conditions ranging from Alzheimer's to schizophrenia (Kem, 2000; Martin et al., 2004). Therefore, the data presented in this manuscript warrant further research regarding the potential therapeutic role of pharmacological agents targeting the $\alpha 7 \mathrm{nAChR}$ for the treatment of global cerebral ischemia.

Peripheral inflammatory responses can exacerbate cerebral ischemia, and peripheral treatment with anti-inflammatory agents has been shown to decrease inflammation and neuronal cell death following ischemia (Spencer et al., 2007). In addition to its central effects, GTS-21 has also been shown to inhibit peripheral inflammatory responses (Pavlov et al., 2006; Rosas-Ballina et al., 2009). Therefore, it is possible that the actions of GTS-21 may result from its ability to inhibit peripheral inflammatory responses to cerebral ischemia; future studies will be necessary to determine the role of central versus peripheral $\alpha 7 \mathrm{nAChR}$ following cerebral ischemia, and whether treatment with GTS-21 prevents the development of behavioral deficits. Importantly, GTS-21 was administered a full $24 \mathrm{~h}$ following CA/CPR, which indicates a wide clinical therapeutic window. In addition, the efficacy of peripherally administered GTS-21 provides a clinically relevant route of drug administration since GTS-21 readily crosses the blood-brain barrier (Mahnir et al., 1998).

Interestingly, while we repeatedly demonstrated the effects of cerebral ischemia on markers of cholinergic functioning, we found no changes in ChT1. One explanation for the selective effects on ChAT and vAChT may result from the fact that they are expressed intracellularly and ChT1 is expressed on the cell surface, and the pathophysiological cascade mechanisms associated with cerebral ischemia may affect these two locations differently. Also, ChAT and vACht share a number of promoters that drive gene expression in similar patterns for both molecules (Cervini et al., 1995). Future studies will be necessary to determine the role of ChT1 following cerebral ischemia.

Together, our data provide evidence that CA/CPR causes a dysregulation of central cholinergic signaling and engenders large increases in neuroinflammation, serum IL-6, and neuronal damage that were effectively mitigated by postischemia treatment with an $\alpha 7 \mathrm{nAChR}$ agonist. These data suggest that $\alpha 7 \mathrm{nAChRs}$ represent a potential target for the pharmacological treatment of global cerebral ischemia following CA/CPR.

\section{References}

Adrie C, Adib-Conquy M, Laurent I, Monchi M, Vinsonneau C, Fitting C, Fraisse F, Dinh-Xuan AT, Carli P, Spaulding C, Dhainaut JF, Cavaillon JM (2002) Successful cardiopulmonary resuscitation after cardiac arrest as a "sepsis-like" syndrome. Circulation 106:562-568.

Allan SM, Tyrrell PJ, Rothwell NJ (2005) Interleukin-1 and neuronal injury. Nat Rev Immunol 5:629-640.

American Heart Association (2002) Heart disease and stroke statistics: 2003 update. Dallas, TX: American Heart Association.

Barone FC, Arvin B, White RF, Miller A, Webb CL, Willette RN, Lysko PG, Feuerstein GZ (1997) Tumor necrosis factor-alpha. A mediator of focal ischemic brain injury. Stroke 28:1233-1244.

Berntson GG, Sarter M, Cacioppo JT (1998) Anxiety and cardiovascular reactivity: the basal forebrain cholinergic link. Behav Brain Res 94:225-248.

Böttiger BW, Teschendorf P, Krumnikl JJ, Vogel P, Galmbacher R, Schmitz B, Motsch J, Martin E, Gass P (1999) Global cerebral ischemia due to cardiocirculatory arrest in mice causes neuronal degeneration and early in- duction of transcription factor genes in the hippocampus. Brain Res Mol Brain Res 65:135-142.

Briggs CA, Anderson DJ, Brioni JD, Buccafusco JJ, Buckley MJ, Campbell JE, Decker MW, Donnelly-Roberts D, Elliott RL, Gopalakrishnan M, Holladay MW, Hui YH, Jackson WJ, Kim DJ, Marsh KC, O’Neill A, Prendergast MA, Ryther KB, Sullivan JP, Arneric SP (1997) Functional characterization of the novel neuronal nicotinic acetylcholine receptor ligand GTS-21 in vitro and in vivo. Pharmacol Biochem Behav 57:231-241.

Bunch TJ, White RD, Gersh BJ, Meverden RA, Hodge DO, Ballman KV, Hammill SC, Shen WK, Packer DL (2003) Long-term outcomes of outof-hospital cardiac arrest after successful early defibrillation. N Engl J Med 348:2626-2633.

Cervini R, Houhou L, Pradat PF, Béjanin S, Mallet J, Berrard S (1995) Specific vesicular acetylcholine transporter promoters lie within the first intron of the rat choline acetyltransferase gene. J Biol Chem 270: $24654-24657$.

Chapman KZ, Dale VQ, Dénes A, Bennett G, Rothwell NJ, Allan SM, McColl BW (2009) A rapid and transient peripheral inflammatory response precedes brain inflammation after experimental stroke. J Cereb Blood Flow Metab 29:1764-1768.

Cooper JR (1994) Unsolved problems in the cholinergic nervous system. J Neurochem 63:395-399.

Danton GH, Dietrich WD (2003) Inflammatory mechanisms after ischemia and stroke. J Neuropathol Exp Neurol 62:127-136.

Debruyne D, Sobrio F, Hinschberger A, Camsonne R, Coquerel A, Barré L (2003) Short-term pharmacokinetics and brain distribution of mecamylamine as a preliminary to carbon-11 labeling for nicotinic receptor investigation. J Pharm Sci 92:1051-1057.

Franklin K, Paxinos G (1996) The mouse brain in stereotaxic coordinates. San Diego, CA: Academic.

Gotti C, Zoli M, Clementi F (2006) Brain nicotinic acetylcholine receptors: native subtypes and their relevance. Trends Pharmacol Sci 27:482-491.

Harukuni I, Bhardwaj A (2006) Mechanisms of brain injury after global cerebral ischemia. Neurol Clin 24:1-21.

Karelina K, Norman GJ, Zhang N, Morris JS, Peng H, DeVries AC (2009) Social isolation alters neuroinflammatory response to stroke. Proc Natl Acad Sci U S A 106:5895-5900.

Kem WR (2000) The brain alpha7 nicotinic receptor may be an important therapeutic target for the treatment of Alzheimer's disease: studies with DMXBA (GTS-21). Behav Brain Res 113:169-181.

Kidwell CS, Latour L, Saver JL, Alger JR, Starkman S, Duckwiler G, Jahan R, Vinuela F, Vinuela F, Kang DW, Warach S (2008) Thrombolytic toxicity: blood brain barrier disruption in human ischemic stroke. Cerebrovasc Dis 25:338-343.

Lambertsen KL, Clausen BH, Babcock AA, Gregersen R, Fenger C, Nielsen HH, Haugaard LS, Wirenfeldt M, Nielsen M, Dagnaes-Hansen F, Bluethmann H, Faergeman NJ, Meldgaard M, Deierborg T, Finsen B (2009) Microglia protect neurons against ischemia by synthesis of tumor necrosis factor. J Neurosci 29:1319-1330.

Lee ST, Chu K, Jung KH, Kang KM, Kim JH, Bahn JJ, Jeon D, Kim M, Lee SK, Roh JK (2010) Cholinergic anti-inflammatory pathway in intracerebral hemorrhage. Brain Res 1309:164-171.

Mahnir V, Lin B, Prokai-Tatrai K, Kem WR (1998) Pharmacokinetics and urinary excretion of DMXBA (GTS-21), a compound enhancing cognition. Biopharm Drug Dispos 19:147-151.

Martin LF, Kem WR, Freedman R (2004) Alpha-7 nicotinic receptor agonists: potential new candidates for the treatment of schizophrenia. Psychopharmacology (Berl) 174:54-64.

Moon JH, Kim SY, Lee HG, Kim SU, Lee YB (2008) Activation of nicotinic acetylcholine receptor prevents the production of reactive oxygen species in fibrillar beta amyloid peptide (1-42)-stimulated microglia. Exp Mol Med 40:11-18.

Neigh GN, Glasper ER, Kofler J, Traystman RJ, Mervis RF, Bachstetter A, DeVries AC (2004) Cardiac arrest with cardiopulmonary resuscitation reduces dendritic spine density in CA1 pyramidal cells and selectively alters acquisition of spatial memory. Eur J Neurosci 20:1865-1872.

Neigh GN, Karelina K, Glasper ER, Bowers SL, Zhang N, Popovich PG, DeVries AC (2009) Anxiety after cardiac arrest/cardiopulmonary resuscitation: exacerbated by stress and prevented by minocycline. Stroke 40:3601-3607.

Norman GJ, Zhang N, Morris JS, Karelina K, Berntson GG, DeVries AC (2010) Social interaction modulates autonomic, inflammatory, and 
depressive-like responses to cardiac arrest and cardiopulmonary resuscitation. Proc Natl Acad Sci U S A 107:16342-16347.

Ohnishi M, Katsuki H, Takagi M, Kume T, Akaike A (2009) Long-term treatment with nicotine suppresses neurotoxicity of, and microglial activation by, thrombin in cortico-striatal slice cultures. Eur J Pharmacol 602:288-293.

Paradis NA, Wenzel V, Southall J (2002) Pressor drugs in the treatment of cardiac arrest. Cardiol Clin 20:61-78, viii.

Pavlov VA, Ochani M, Gallowitsch-Puerta M, Ochani K, Huston JM, Czura CJ, Al-Abed Y, Tracey KJ (2006) Central muscarinic cholinergic regulation of the systemic inflammatory response during endotoxemia. Proc Natl Acad Sci U S A 103:5219-5223.

Pavlov VA, Ochani M, Yang LH, Gallowitsch-Puerta M, Ochani K, Lin X, Levi J, Parrish WR, Rosas-Ballina M, Czura CJ, Larosa GJ, Miller EJ, Tracey KJ, Al-Abed Y (2007) Selective alpha7-nicotinic acetylcholine receptor agonist GTS-21 improves survival in murine endotoxemia and severe sepsis. Crit Care Med 35:1139-1144.

Popovich PG, Wei P, Stokes BT (1997) Cellular inflammatory response after spinal cord injury in Sprague-Dawley and Lewis rats. J Comp Neuroi 3:443-464.

Püttgen HA, Pantle H, Geocadin RG (2009) Management of cardiac arrest patients to maximize neurologic outcome. Curr Opin Crit Care 15: $118-124$.

Rosas-Ballina M, Goldstein RS, Gallowitsch-Puerta M, Yang L, Valdés-Ferrer SI, Patel NB, Chavan S, Al-Abed Y, Yang H, Tracey KJ (2009) The selective alpha7 agonist GTS-21 attenuates cytokine production in human whole blood and human monocytes activated by ligands for TLR2, TLR3, TLR4, TLR9, and RAGE. Mol Med 15:195-202.

Sarter M, Parikh V (2005) Choline transporters, cholinergic transmission and cognition. Nat Rev Neurosci 6:48-56.

Schmued LC, Hopkins KJ (2000) Fluoro-Jade B: a high affinity fluorescent marker for the localization of neuronal degeneration. Brain Res 874: 123-130.

Sharma G, Vijayaraghavan S (2002) Nicotinic receptor signaling in nonexcitable cells. J Neurobiol 53:524-534.
Smith CJ, Emsley HC, Gavin CM, Georgiou RF, Vail A, Barberan EM, del Zoppo GJ, Hallenbeck JM, Rothwell NJ, Hopkins SJ, Tyrrell PJ (2004) Peak plasma interleukin-6 and other peripheral markers of inflammation in the first week of ischemic stroke correlate with brain infarct volume, stroke severity and long-term outcome. BMC Neurol 4:2.

Spencer SJ, Mouihate A, Pittman QJ (2007) Peripheral inflammation exacerbates damage after global ischemia independently of temperature and acute brain inflammation. Stroke 38:1570-1577.

Suzuki S, Tanaka K, Suzuki N (2009) Ambivalent aspects of interleukin-6 in cerebral ischemia: inflammatory versus neurotrophic aspects. J Cereb Blood Flow Metab 29:464-479.

Tracey KJ (2009) Reflex control of immunity. Nat Rev Immunol 9: $418-428$.

Wang Q, Tang XN, Yenari MA (2007) The inflammatory response in stroke. J Neuroimmunol 184:53-68.

Weil ZM, Norman GJ, Barker JM, Su AJ, Nelson RJ, Devries AC (2008) Social isolation potentiates cell death and inflammatory responses after global ischemia. Mol Psychiatry 13:913-915.

Weil ZM, Karelina K, Su AJ, Barker JM, Norman GJ, Zhang N, Devries AC, Nelson RJ (2009) Time-of-day determines neuronal damage and mortality after cardiac arrest. Neurobiol Dis 36:352-360.

Wenk GL, Willard LB (1998) The neural mechanisms underlying cholinergic cell death within the basal forebrain. Int J Dev Neurosci 16:729-735.

Wenk GL, McGann K, Hauss-Wegrzyniak B, Rosi S (2003) The toxicity of tumor necrosis factor-alpha upon cholinergic neurons within the nucleus basalis and the role of norepinephrine in the regulation of inflammation: implications for Alzheimer's disease. Neuroscience 121:719-729.

Yang GY, Gong C, Qin Z, Ye W, Mao Y, Bertz AL (1998) Inhibition of TNFalpha attenuates infarct volume and ICAM-1 expression in ischemic mouse brain. Neuroreport 9:2131-2134.

Young JM, Shytle RD, Sanberg PR, George TP (2001) Mecamylamine: new therapeutic uses and toxicity/risk profile. Clin Ther 23:532-565.

Youngquist ST, Niemann JT, Heyming TW, Rosborough JP (2009) The CNS cytokine response to global ischemia following resuscitation from ventricular fibrillation in a porcine model. Resuscitation 80:249-252. 